\title{
Validation of bovine glycomacropeptide as an intestinal anti-inflammatory nutraceutical in the lymphocyte-transfer model of colitis
}

\author{
Mercedes Ortega-González ${ }^{1} \dagger$, Fermín Capitán-Cañadas ${ }^{1} \dagger$, Pilar Requena ${ }^{1} \ddagger$, Borja Ocón ${ }^{2}$, \\ Isabel Romero-Calvo ${ }^{1}$, Carlos Aranda ${ }^{1}$, María Dolores Suárez ${ }^{1}$, Antonio Zarzuelo ${ }^{2}$, \\ Fermín Sánchez de Medina ${ }^{2}$ and Olga Martínez-Augustin ${ }^{1 *}$ \\ ${ }^{1}$ Department of Biochemistry and Molecular Biology II, Centro de Investigación Biomédica en Red de Enfermedades \\ Hepáticas y Digestivas (CIBERehd), School of Pharmacy, Instituto de Investigación Biosanitario (IBIG), University of \\ Granada, Campus de Cartuja s/ $n, 18071$ Granada, Spain \\ ${ }^{2}$ Department of Pharmacology, Centro de Investigación Biomédica en Red de Enfermedades Hepáticas y Digestivas \\ (CIBERehd), School of Pharmacy, Instituto de Investigación Biosanitario (IBIG), University of Granada, Campus de \\ Cartuja s/n, 18071 Granada, Spain
}

(Submitted 3 July 2013 - Final revision received 7 October 2013 - Accepted 7 October 2013 - First published online 14 November 2013)

\begin{abstract}
Milk $\kappa$-casein-derived bovine glycomacropeptide (GMP) exerts immunomodulatory effects. It exhibits intestinal anti-inflammatory activity in chemically induced models of colitis. However, to validate its clinical usefulness as a nutraceutical, it is important to assess its effects in a model with a closer pathophysiological connection with human inflammatory bowel disease. Therefore, in the present study, we used the lymphocyte-transfer model of colitis in mice and compared the effects of GMP in this model with those obtained in the dextran sulphate sodium (DSS) model. GMP (15 mg/d) resulted in higher body-weight gain and a reduction of the colonic damage score and myeloperoxidase (MPO) activity in Rag $1^{-1-}$ mice with colitis induced by the transfer of naive T cells. The colonic and ileal weight:length ratio was decreased by approximately $25 \%$, albeit non-significantly. GMP treatment reduced the percentage of $\mathrm{CD}^{+}{ }^{+}$interferon (IFN)- $\gamma^{+}$cells in mesenteric lymph nodes (MLN). The basal production of IL-6 by MLN obtained from the GMP-treated mice ex vivo was augmented. However, concanavalin A-evoked production was similar. The colonic expression of regenerating islet-derived protein $3 \gamma, \mathrm{S} 100 \mathrm{~A} 8$, chemokine (C-X-C motif) ligand 1 and IL- $1 \beta$ was unaffected by GMP, while that of TNF- $\alpha$ and especially IFN- $\gamma$ was paradoxically increased. In the DSS model, GMP also reduced the activity of colonic MPO, but it failed to alter weight gain or intestinal weight:length ratio. GMP augmented the production of IL-10 by MLN cells and was neutral towards other cytokines, except exhibiting a trend towards increasing the production of IL-6. The lower effect was attributed to the lack of the effect of GMP on epithelial cells. In conclusion, GMP exerts intestinal anti-inflammatory effects in lymphocyte-driven colitis.
\end{abstract}

Key words: Glycomacropeptide: Casein macropeptide: Lymphocyte-transfer colitis: Dextran sulphate sodium: Inflammatory bowel disease

Nutraceuticals are food-related products that confer health benefits on the consumer beyond their basic nutritional value. In the last few years, there has been a great interest in nutraceuticals and functional foods, since they open up the possibility of deterring disease (to a certain extent) as an add-on to regular diet. Although their properties are partly drug like, their origin as part of foodstuffs and their extremely low toxicity are especially attractive to the general public. Not surprisingly, the food industry has been particularly active in the search and marketing of new products of this type. However, there is an obvious risk of overselling the claimed virtues of a given nutraceutical. Current regulations in Europe (EC 432/2012) require the demonstration of specific qualities in terms of physiological benefits or disease prevention.

One of the conditions where nutraceuticals and functional foods may play a role is inflammatory bowel disease (IBD).

\footnotetext{
Abbreviations: AP, alkaline phosphatase; CXCL1, chemokine (C-X-C motif) ligand 1; DSS, dextran sulphate sodium; GMP, glycomacropeptide; IBD, inflammatory bowel disease; IFN, interferon; MLN, mesenteric lymph node; MPO, myeloperoxidase; REG3 $\gamma$, regenerating islet-derived protein 3 gamma; TNBS, trinitrobenzenesulphonic acid.
}

*Corresponding author: O. Martínez-Augustin, fax +34958 248960, email omartine@ugr.es

$\dagger$ Both authors contributed equally to the present study.

‡ Present address: Department of Parasitology, Liverpool School of Tropical Medicine, Pembroke Place, L3 5QA Liverpool, UK. 
Comprising ulcerative colitis and Crohn's disease, IBD is characterised by chronic and relapsing inflammation of the intestine, resulting in a significant deterioration of the quality of life of patients. Furthermore, the prevalence of IBD is slowly increasing $^{(1,2)}$. IBD is considered to develop as the result of an insufficiently characterised interplay of genetic, environmental, microbial and immunological factors, involving an uncontrolled response to luminal antigens that are innocuous for the normal population. These processes have long been thought to be related to augmented adaptive immunity responses, but it has also been proposed that a defect in innate immunity may paradoxically underlie the aetiology of $\operatorname{IBD}^{(3-6)}$. Whatever be the exact mechanism, IBD is regularly managed pharmacologically with drugs that down-regulate the immune system such as corticoids, infliximab, aminosalicylates and azathioprine. All these agents have a plethora of serious adverse effects that limit their application and they are not effective in all patients. Hence, the search for new treatments with a low profile of adverse effects is much warranted ${ }^{(2)}$.

Bovine glycomacropeptide (GMP), also referred to as casein macropeptide, is a sixty-four-amino acid peptide that contains varying amounts ( $0-5$ units) of $\mathrm{N}$-acetylneuraminic (sialic) acid. This peptide results from the enzymatic hydrolysis of milk $\kappa$-casein in the bovine stomach due to the action of chymosin (pepsin in humans) ${ }^{(7)}$. In addition, GMP is present in milk whey in amounts ranging from 10 to $15 \%$ as a result of the action of the same enzyme during the cheese-making process. Therefore, there is a substantial natural exposure to this peptide. GMP has nutritional value because its amino acid profile is high in branched-chain amino acids and lacks aromatic amino acids, therefore being one of the few naturally occurring proteins safe for consumption by individuals with phenylketonuria and perhaps useful in the management of some liver diseases ${ }^{(8,9)}$. On the other hand, a number of biological activities have been ascribed to GMP. We have previously established that GMP has intestinal antiinflammatory activity in experimental models of $\operatorname{IBD}^{(10-13)}$. However, this is probably insufficient evidence to support the use of GMP as a nutraceutical, because the trinitrobenzene sulphonic acid (TNBS) and dextran sulphate sodium (DSS) rat models used previously are not strictly chronic (i.e. they heal with time) and they are not lymphocyte driven as in human disease. Some authors have advocated the use of other IBD models to achieve a better prediction of human bioactivity ${ }^{(14)}$, such as colitis induced by the transfer of naïve $\mathrm{T}$ lymphocytes into immunodeficient mice, anticipating that the validation of nutritional or pharmacological treatments of IBD should include one such model. Therefore, in the present study, we set out to test the activity of GMP in lymphocyte-transfer colitis in mice. Among the parameters evaluated was the activity of myeloperoxidase (MPO), a neutrophil marker that is widely used as an index of colitis activity in preclinical models of IBD. Since tissue damage in IBD is the result of an exacerbated inflammatory response, a normalisation of this parameter is considered an improvement in disease evolution. Some other mediators related to the innate immune system such as regenerating islet-derived protein $3 \gamma$ (REG3 $\gamma$, an antimicrobial peptide expressed by intestinal epithelial cells), S100A8 (also a prominent neutrophil marker and a component of calprotectin), chemokine (C-X-C motif) ligand 1 (CXCL1, a chemokine with neutrophil chemoattractant activity) and IL-1 $\beta$ (a proinflammatory cytokine mainly produced by macrophages) were also studied. The results obtained are consistent with a beneficial effect of the peptide.

\section{Materials and methods}

\section{Reagents}

Except where indicated, all the reagents and primers were obtained from Sigma. Retrotranscription was carried out using the iScriptTM cDNA Synthesis Kit, and iTM SYBR Green Supermix was used for amplification (Bio-Rad). Antibodies were purchased from Cayman Technologies and Sigma. Mouse ELISA kits were obtained from eBioscience. DSS was obtained from ICN Biomedicals. GMP (BioPURE$\mathrm{GMP}^{\mathrm{TM}}$ ) was a kind gift from Davisco Foods International, Inc. According to the manufacturer, the GMP content was $93 \%$, while fat and lactose contents accounted for $0.2 \%$ and less than $1 \%$, respectively.

\section{Animals}

Female C57BL/6 wild-type and Rag1 ${ }^{-/-}$mice were obtained from Jackson Laboratory, housed in Makrolon cages and maintained in the animal facilities of the University of Granada in air-conditioned animal quarters under a $12 \mathrm{~h}$ light- $12 \mathrm{~h}$ dark cycle. The mice were given free access to tap water and food. All the animal procedures carried out in the present study were in accordance with the Directive for the Protection of Vertebrate Animals used for Experimental and other Scientific Purposes of the European Union (86/609/EEC) and were approved by the Animal Welfare Committee of the University of Granada (reference 710).

\section{Induction of transfer colitis and experimental design}

Female C57BL/6 mice were killed by cervical dislocation, and the spleens were extracted aseptically. Cell suspensions were obtained by disrupting the tissues between dissecting forceps in a medium. After centrifugation, the cells were cleared of erythrocytes by suspension in a hypotonic lysis buffer $\left(0 \cdot 15 \mathrm{M}-\mathrm{NH}_{4} \mathrm{Cl}, \quad 10 \mathrm{~mm}-\mathrm{KHCO}_{3}\right.$ and $0 \cdot 1 \mathrm{~mm}-\mathrm{Na}_{2}$ EDTA. $2 \mathrm{H}_{2} \mathrm{O}$, $\mathrm{pH} 7 \cdot 3$ ) for $30 \mathrm{~min}$ on ice. The cells were filtered using a $70 \mu \mathrm{M}$ filter (BD Falcon ${ }^{\mathrm{TM}}$ cell strainer; Becton Dickinson) to obtain a mononuclear suspension. Mononuclear cells were washed and suspended in MACS buffer. $\mathrm{CD} 4^{+} \mathrm{CD}_{2} 2 \mathrm{~L}^{+} \mathrm{T}$ cells were isolated from spleen cells using $\mathrm{CD}^{+}{ }^{+} \mathrm{CD}_{2} \mathrm{~L}^{+} \mathrm{T}$ Cell Isolation Kit II (Miltenyi Biotec). In the first step, non-CD ${ }^{+}$T cells were indirectly magnetically labelled with a cocktail of biotinconjugated antibodies and AntiBiotin MicroBeads. The labelled cells were subsequently depleted by separation over a MACS ${ }^{\circledR}$ column. In the second step, $\mathrm{CD} 4^{+} \mathrm{CD}_{2} 2 \mathrm{~L}^{+} \mathrm{T}$ cells were directly labelled with CD62L (L-selectin) MicroBeads and isolated by positive selection from the pre-enriched $\mathrm{CD}_{4}{ }^{+} \mathrm{T}$-cell fraction. $\mathrm{CD}^{+}$CD62L T cells were eluted in $100 \mu \mathrm{l}$ of sterile PBS and 
administered via the intraperitoneal route to $\mathrm{C} 57 \mathrm{BL} / 6 \mathrm{Rag} 1^{-1-}$ mice $\left(10^{6}\right.$ cells per mouse). Rag $1^{-/-}$control mice were administered sterile PBS.

The status of the mice was monitored by general examination and specifically controlling body-weight evolution, beginning the experiment after a body-weight loss of $10 \%$ (about 8 weeks after the transfer). Colitic mice were randomly assigned to two different groups: GMP group and transfer colitis group. The GMP group ( $n$ 7) was orally administered $15 \mathrm{mg} / \mathrm{d}$ of GMP, while the transfer colitis group ( $n$ 8) was administered a vehicle (distilled water). A non-colitic C group ( $\operatorname{Rag} 1^{-/-}$mice administered $100 \mu \mathrm{l}$ of sterile PBS) was also included in the experiment ( $n 6$ ). Treatment was continued until the mice were killed after $13 \mathrm{~d}$ by cervical dislocation.

\section{Induction of colitis by dextran sulphate sodium and experimental design}

A total of twenty-two female C57BL/6 mice were used. Colitis was induced by adding DSS to the drinking-water for $8 \mathrm{~d}^{(10,15)}$. We selected the experimental conditions to achieve a mild-tomoderate degree of colitis by using $2 \% \mathrm{w} / \mathrm{v}$ of DSS. The status of the mice was monitored by general examination and specifically by means of the disease activity index, a combined score for weight loss, diarrhoea and haematochezia, which are three main signs of pathology in this model ${ }^{(16)}$. Food intake, water intake and body weight were measured every day.

Mice were randomly assigned to three different groups. The control (C) group ( $n$ 6) did not receive DSS and was administered water daily by means of a gastro-oesophageal catheter. The remainder of the mice drank DSS-supplemented water, and received by gavage either $15 \mathrm{mg} / \mathrm{d}$ of GMP (GMP group, $n$ ) or orally administered vehicle (distilled water, DSS group, $n$ 8). Treatment was started $2 \mathrm{~d}$ before DSS supplementation and was continued until the mice were killed after $10 \mathrm{~d}$ by cervical dislocation.

\section{Assessment of colonic damage}

The entire colon was removed, gently flushed with saline and placed on an ice-cold plate, cleaned of fat and mesentery, and blotted on filter paper. Each specimen was weighed, and its length was measured under a constant load ( $2 \mathrm{~g}$ ). The large intestine was longitudinally opened and scored for visible damage by a blinded observer. Transfer colitis was scored on a scale of $0-15$ according to the following criteria: adhesions (0-3); obstruction (0-2); hyperaemia (0-3); thickness $(0-5)$; ulceration $(0-2)$. DSS colitis was scored on a scale of $0-13$ according to the following criteria: adhesions (0-3); hyperaemia (0-3); fibrosis (rigidity, 0-3); deformation (0-2); thickening (0-2). A small segment was dissected from the intestine and used for RNA isolation. The colon was subsequently cut longitudinally into several pieces for the determination of biochemical parameters. The fragments were immediately frozen in liquid $\mathrm{N}_{2}$ and kept at $-80^{\circ} \mathrm{C}$ until use. Formalin-fixed colonic tissue was cut and stained with haematoxylin and eosin. The activities of MPO and alkaline phosphatase (AP) were measured spectrophotometrically as described previously ${ }^{(17,18)}$, and they are expressed as $\mathrm{mU} / \mathrm{mg}$ protein. In addition, the sensitivity to the AP inhibitor levamisole was assessed, and it is expressed as a percentage of inhibition.

\section{Analysis of gene expression by RT-PCR analysis}

Total RNA was obtained by the TRIzol method (Invitrogen), and $1 \mu \mathrm{g}$ was retrotranscribed and specific RNA sequences were amplified with a Stratagene MX3005P real-time PCR device (Agilent) using the following primers: 18S sense: ACA CGG ACA GGA TTG ACA GAT TG, 18S antisense: GCC AGA GTC TCG TTC GTT ATC G; S100A8 sense: GCC CTC TAC AAG AAT GAC TTC AAG, S100A8 antisense: ATC ACC ATC GCA AGG AAC TCC; IL-1 $\beta$ sense: AAG GGC TGC TTC CAA ACC TTT GAC, IL-1 $\beta$ antisense: TGC CTG AAG CTC TTG TTG ATG TGC; TNF- $\alpha$ sense: CGT GGA ACT GGC AGA AGA GG, TNF$\alpha$ antisense: CAG GAA TGA GAA GAG GCT GAG AC; interferon (IFN)- $\gamma$ sense: GCT CTG AGA CAA TGA ACG CTA CAC, IFN- $\gamma$ antisense: TTC TTC CAC ATC TAT GCC ACT TGA G; CXCL1 sense: CCG AAG TCA TAG CCA CAC TCA AG, CXCL1 antisense: ACC AGA CAG GTG CCA TCA GAC; REG3 $\gamma$ sense: CAG AGG TGG ATG GGA GTG GAG, REG3 $\gamma$ antisense: CAC AGT GAT TGC CTG AGG AAG AAG AG.

\section{Secretion of cytokines by mesenteric lymph node cells}

Mesenteric lymph nodes (MLN) were extracted from the mice using a sterile technique and dissected mechanically. Cells were washed once with fresh medium and were filtered using a $70 \mu \mathrm{M}$ filter (BD Falcon ${ }^{\mathrm{TM}}$ cell strainer, Reference 352350; Becton Dickinson) to obtain a mononuclear suspension, mostly of T cells. The cells were incubated in RPMI 1640 medium containing fetal bovine serum (10\%), $2 \mathrm{~mm}$-L-glutamine, $100 \mathrm{U} / \mathrm{ml}$ penicillin, $0.1 \mathrm{mg} / \mathrm{ml}$ streptomycin, $2.5 \mathrm{mg} / \mathrm{ml}$ amphotericin B and $0.05 \mathrm{~mm}-$ mercaptoethanol. The cells were cultured at $10^{6}$ cells $/ \mathrm{ml}$ and stimulated with concanavalin $\mathrm{A}$ at a final concentration of $5 \mu \mathrm{g} / \mathrm{ml}$. Concanavalin A is a polyclonal T-cell stimulant that evokes a surge in the secretion of cytokines by MLN cells, which is typically enhanced in colitic animals. Cell-culture medium was collected after $48 \mathrm{~h}$ and assayed for cytokine content by commercial ELISA. The cytokines assayed were IL-6, IL-10, IL-17, IFN- $\gamma$ and TNF- $\alpha$. Plates (Nunc ${ }^{\mathrm{TM}}$ Inmuno plate) were read at $450 \mathrm{~nm}$ using a plate reader (Tecan, model Sunrise-basic).

\section{Epithelial cell experiments}

Using GMP and intestinal epithelial cells, three different in vitro experiments were carried out. First, the effect of GMP (0.01-1 g/l) on the secretion of IL- 8 by confluent HT29 cell monolayers was assessed by ELISA (R\&D Systems). Second, the effect of GMP on bacterial invasion in IEC18 cells was studied. Escherichia coli K12 and LF82 strains (kindly provided by Dr Arlette Darfeuille Michaud) expressing green fluorescent protein were used. Bacteria were grown routinely in lysogeny broth supplemented with $20 \mu \mathrm{g} / \mathrm{ml}$ of gentamicin overnight at $37^{\circ} \mathrm{C}$ with shaking. For every experiment, bacteria were freshly 
grown overnight. The invasion assays were carried out in IEC18 cell monolayers cultured in twelve-well plates. GMP (5-20 g/1) was added to the medium $24 \mathrm{~h}$ before and during the invasion assays. Each monolayer was infected with $1 \mathrm{ml}$ of the cell-culture medium without antibiotics at a multiplicity of infection of 100 bacteria per epithelial cell. After $4 \mathrm{~h}$ of incubation, infected monolayers were washed three times with Hanks balanced salt solution (HBSS) and fresh cell-culture medium containing $100 \mathrm{mg} / \mathrm{l}$ of kanamycin, $500 \mathrm{mg} / \mathrm{l}$ of streptomycin and $500000 \mathrm{UI} / 1$ of penicillin was added to kill extracellular bacteria. After incubation for an additional hour, monolayers were washed three times again with HBSS. The cells were collected by trypsinisation and analysed by flow cytometry (FACSCalibur, $\mathrm{BD}$ ), and results are expressed as a percentage of green-positive cells, each positive event representing a cell containing green fluorescent protein-expressing bacteria.

Third, the effect of GMP on wound was assessed. Rat epithelial IEC18 cells were grown to confluence in twentyfour-well dishes and were mechanically wounded by parallel scratches using a sterile pipet tip. Medium present on the wounded monolayers was replaced with a normal medium or a normal medium containing GMP $1 \mathrm{~g} / \mathrm{ml}$ and incubated for $24 \mathrm{~h}$. Photomicrographs of the lineal wounds were taken using the $4 \times$ objective of an Olympus IX71S8F- 3 microscope at the moment of wounding and at 6, 11 and $24 \mathrm{~h}$, and the area of each wound was quantified with the Image $J$ software (National Institutes of Health).

IEC18 (ECACC 88011801) and HT29 (ECACC 91072201) cells were supplied by the Cell Culture Facility of the University of Granada and were grown in Dulbecco's modified Eagle's Medium supplemented with $10 \%$ fetal bovine serum (Boehringer Mannheim), $2 \mathrm{mm-L-glutamine,} 100 \mathrm{mg} / 1$ streptomycin, $100000 \mathrm{UI} / 1$ penicillin and $2.5 \mathrm{mg} / 1$ amphotericin $\mathrm{B}$ in a humidified $5 \% \mathrm{CO}_{2}$ atmosphere at $37^{\circ} \mathrm{C}$.

\section{Statistical analysis}

In all the experiments, samples were run in triplicate, and results are expressed as means with their standard errors. Differences among the means were tested for statistical significance by one-way ANOVA and a posteriori Fisher least significant difference tests on preselected pairs. All the analyses were carried out with the SigmaStat 3.5 program (Jandel Corporation). Differences were considered significant at $P<0.05$.

\section{Results}

\section{Lymphocyte-transfer colitis}

Rag $1^{-/-}$mice were monitored for 8 weeks after lymphocyte transfer for body-weight evolution and overall status. The mice exhibited body-weight loss (10\% average) and were randomised for treatment with GMP or vehicle. Hence, this is a post-treatment protocol. The vehicle-administered mice exhibited a relatively stable body weight, which was slightly increased after $13 \mathrm{~d}$ (Table 1). Food intake and water intake were essentially normal (data not shown). The colon appeared thickened, with hyperaemia but with no overt signs of ulceration, obstruction or adhesion (Table 1). The resulting damage score was significantly increased. At the microscopic level, intense mucosal infiltration, crypt elongation and occasional epithelial erosions were observed (data not shown). The ileum was also thickened (29.6 (sE 4.9) v. 21.9 (sE 4.9) $\mathrm{mg} / \mathrm{cm} ; P<0.05)$ and there was splenomegaly (5.4 (SE 3.5) v. 1.3 (SE 0.1), spleen:body weight ratio $\times 1000, P<0 \cdot 05)$.

At the biochemical level, colitis was characterised by a 2 -fold increase in the activity of MPO and a 4-fold increase in that of AP (Figs. 1 and 2(a)). The sensitivity to the specific AP inhibitor levamisole was augmented (Fig. 2(b)). The mRNA levels of REG3 $\gamma$, S100A8, CXCL1, IL-1 $\beta$, TNF- $\alpha$ and IFN- $\gamma$ were significantly increased (Fig. 3). MLN were enriched in $\mathrm{CD}^{+}$ IFN- $\gamma^{+}$cells (Fig. 4), and the MLN cells exhibited an augmented production of cytokines.

GMP resulted in higher body-weight gain (despite a similar food intake) and a reduction of the colonic damage score and ileal (26.5 (se 4.3) v. 29.6 (sE 4.9) $\mathrm{mg} / \mathrm{cm} ; P>0.05)$ and colonic weight:length ratio (Table 1 ), although these did not reach statistical significance. Histological analysis indicated that the features of the treated mice were similar to those of the control mice (data not shown). The activity of MPO was virtually normalised (Fig. 1), while that of AP was reduced by $17 \%$, but without reaching significance (Fig. 2(a)). The sensitivity of AP to levamisole was unaffected (Fig. 2(b)). The colonic expression of REG3 $\gamma$, S100A8, CXCL1 and IL-1 $\beta$ was unaffected by GMP. Conversely, the colonic expression of TNF- $\alpha$ and especially IFN- $\gamma$ was up-regulated (Fig. 3). GMP treatment reduced the percentage of $\mathrm{CD}^{+}$IFN- $\gamma^{+}$cells in MLN (Fig. 4(a)). The basal production of IL-6 by MLN cells obtained from the GMP-treated mice ex vivo was markedly increased

Table 1. Macroscopic damage parameter values of transfer colitic mice and body weight (Mean values with their standard errors)

\begin{tabular}{|c|c|c|c|c|c|c|c|c|}
\hline & \multicolumn{2}{|c|}{$\begin{array}{l}\text { Body weight } \\
\text { (\% initial weight) }\end{array}$} & \multicolumn{2}{|c|}{ Damage score } & \multicolumn{2}{|c|}{$\begin{array}{l}\text { Colon weight: } \\
\text { length ratio } \\
(\mathrm{mg} / \mathrm{cm})\end{array}$} & \multicolumn{2}{|c|}{ Colon length $(\mathrm{cm})$} \\
\hline & Mean & SE & Mean & $\mathrm{SE}$ & Mean & SE & Mean & SE \\
\hline Control & $116 \cdot 0$ & 1.7 & 0 & 0 & 21.6 & 1.4 & $7 \cdot 1$ & 0.2 \\
\hline Transfer colitis & 101.9 & 2.5 & 1.3 & 0.5 & $54 \cdot 3^{*}$ & $6 \cdot 3$ & $9 \cdot 1$ & 0.2 \\
\hline GMP & $104 \cdot 0$ & 3.4 & $1 \cdot 0$ & 0.5 & $46 \cdot 4^{*}$ & $4 \cdot 8$ & $9 \cdot 0$ & 0.4 \\
\hline
\end{tabular}

GMP, glycomacropeptide.

${ }^{*}$ Mean values were significantly different from those of the control group $(P<0.05)$. 


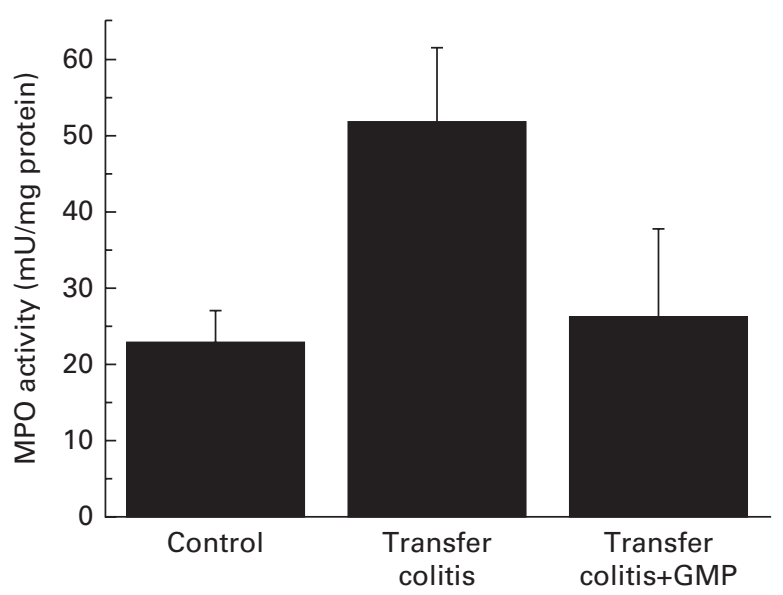

Fig. 1. Colonic myeloperoxidase (MPO) activity in mice with lymphocytedriven colitis. Chronic colitis was induced in mice and they were then treated with glycomacropeptide (GMP; $15 \mathrm{mg} / \mathrm{kg}$ ) or vehicle for $13 \mathrm{~d}$. MPO activity was measured spectrophotometrically. Values are means, with standard errors represented by vertical bars.

(Fig. 4(d)). The basal production of IL-17, IFN- $\gamma$ and TNF- $\alpha$ displayed a similar but much weaker trend, significant only for IL-17. However, concanavalin A-evoked production was similar in all the cases (Fig. 4). There was no effect on spleen size (data not shown).

\section{Dextran sulphate sodium colitis}

The administration of drinking-water supplemented with $2 \%$ DSS to the mice resulted in diarrhoea, haematochezia and body-weight loss (Fig. 5), with an increased disease activity index (data not shown). The colon was thickened and shortened, resulting in an increased weight:length ratio (Table 2). The mucosa exhibited intense hyperaemia and fibrosis, which gave rise to a substantially augmented damage score (Table 2 ). The colitic mice also had splenomegalia (2.8 (SE 0.15) v. 4.0 (SE 0.32 ), spleen:body weight ratio $\times 1000, P<0.05$, control $v$. DSS). The activity of colonic MPO was greatly increased (Fig. 6), while that of AP was augmented approximately 3-fold (Fig. 7(a)). The sensitivity of AP to levamisole was not significantly affected (Fig. 7(b)). The basal production of cytokines by MLN cells ex vivo was negligible (data not shown). Upon concanavalin A stimulation, there was a surge in the release of IL-17 and IL-10, while the release of IL- 6 , TNF- $\alpha$ and IFN- $\gamma$ exhibited only a non-significant trend to increase (Fig. 8).

Pre-treatment with GMP reduced the activity of colonic MPO by about $50 \%$ (Fig. 6), but failed to alter weight gain/disease activity index, colonic weight:length ratio and damage score, AP activity or splenomegalia (Table 2 and Figs. 5-7). Interestingly, GMP augmented the production of IL-10 by MLN cells ex vivo (Fig. 8), while it was essentially neutral towards other cytokines. It also exhibited a clear trend to increase the production of IL-6 (Fig. 8(a)), although without reaching statistical significance.

\section{Effect of glycomacropeptide on intestinal epithelial cells}

The difference observed between the effect of GMP in lymphocyte-transfer colitis and that of GMP in DSS-induced colitis prompted us to assess the effects of the peptide on intestinal epithelial cells. As shown in Fig. 9, there was no effect of GMP on epithelial IL-8 secretion, wound repair or bacterial invasion.

\section{Discussion}

The main goal of the present study was to validate the intestinal anti-inflammatory activity of GMP using a truly chronic, lymphocyte-driven model of IBD ${ }^{(14,19)}$. This model is characterised by progressive expansion of the transferred T-lymphocyte population, with a predominance of $\mathrm{T}$ helper type $1 / \mathrm{T}$ helper type 17 cells and a paucity of $\mathrm{T}$ regulatory cells, resulting in intestinal inflammation, which mainly affects the colon. The process is chronic and may remain relatively stable for weeks or deteriorate slowly until animal death (spontaneous or by euthanasia due to ethical reasons). Despite the obvious advantages of using a model more closely resembling human $\mathrm{IBD}^{(14,19)}$, it poses practical problems for the investigation of bioactive products, compared with chemical models.
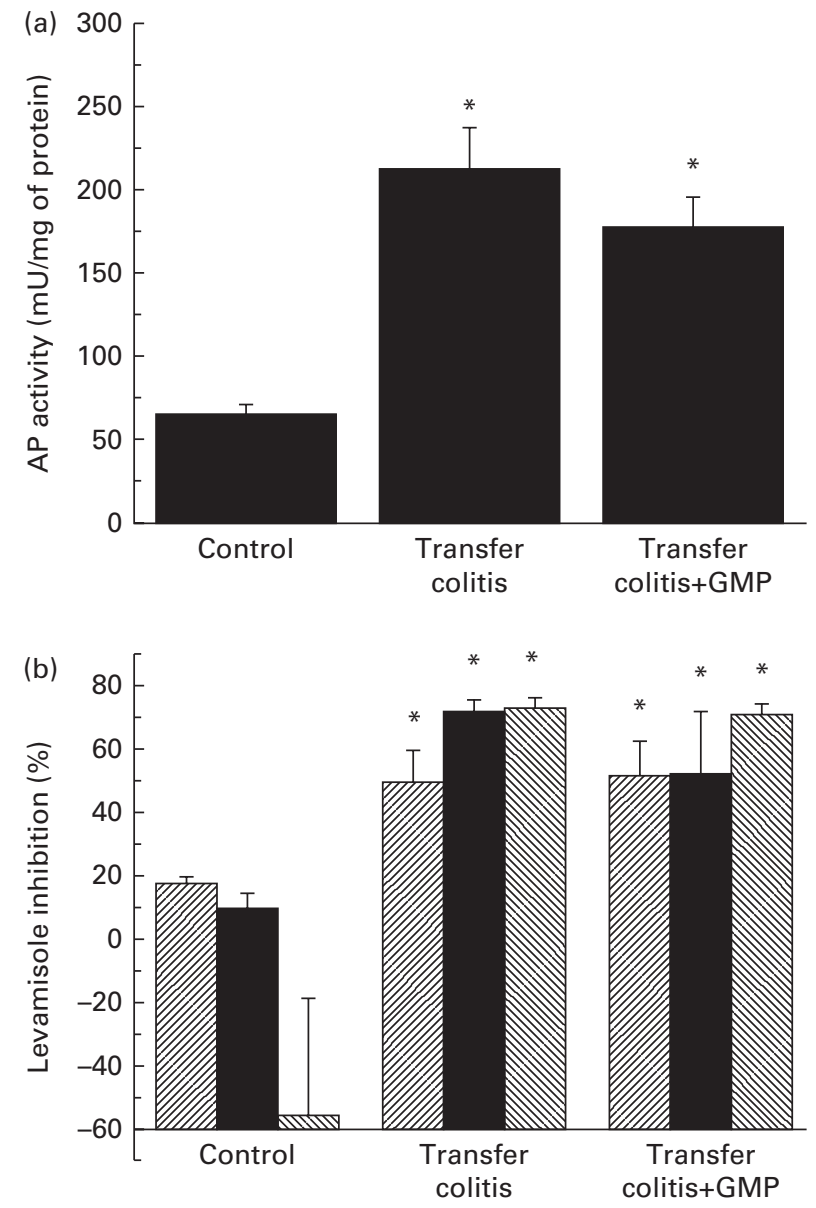

Fig. 2. Colonic alkaline phosphatase (AP) activity in mice with lymphocyte-driven colitis. Chronic colitis was induced in mice and they were then treated with glycomacropeptide (GMP; $15 \mathrm{mg} / \mathrm{kg}$ ) or vehicle for $13 \mathrm{~d}$. AP activity was measured spectrophotometrically. (a) AP activity, (b) Inhibition of AP activity by levamisole in vitro. Values are means, with standard errors represented by vertical bars. * Mean values were significantly different from those of the control group $(P<0.05)$. $\gtrsim$, Levamisole $0.1 \mathrm{~mm} ; \square$, levamisole $1 \mathrm{~mm} ; \mathbb{\mathbb { }}$, levamisole $10 \mathrm{~mm}$. 

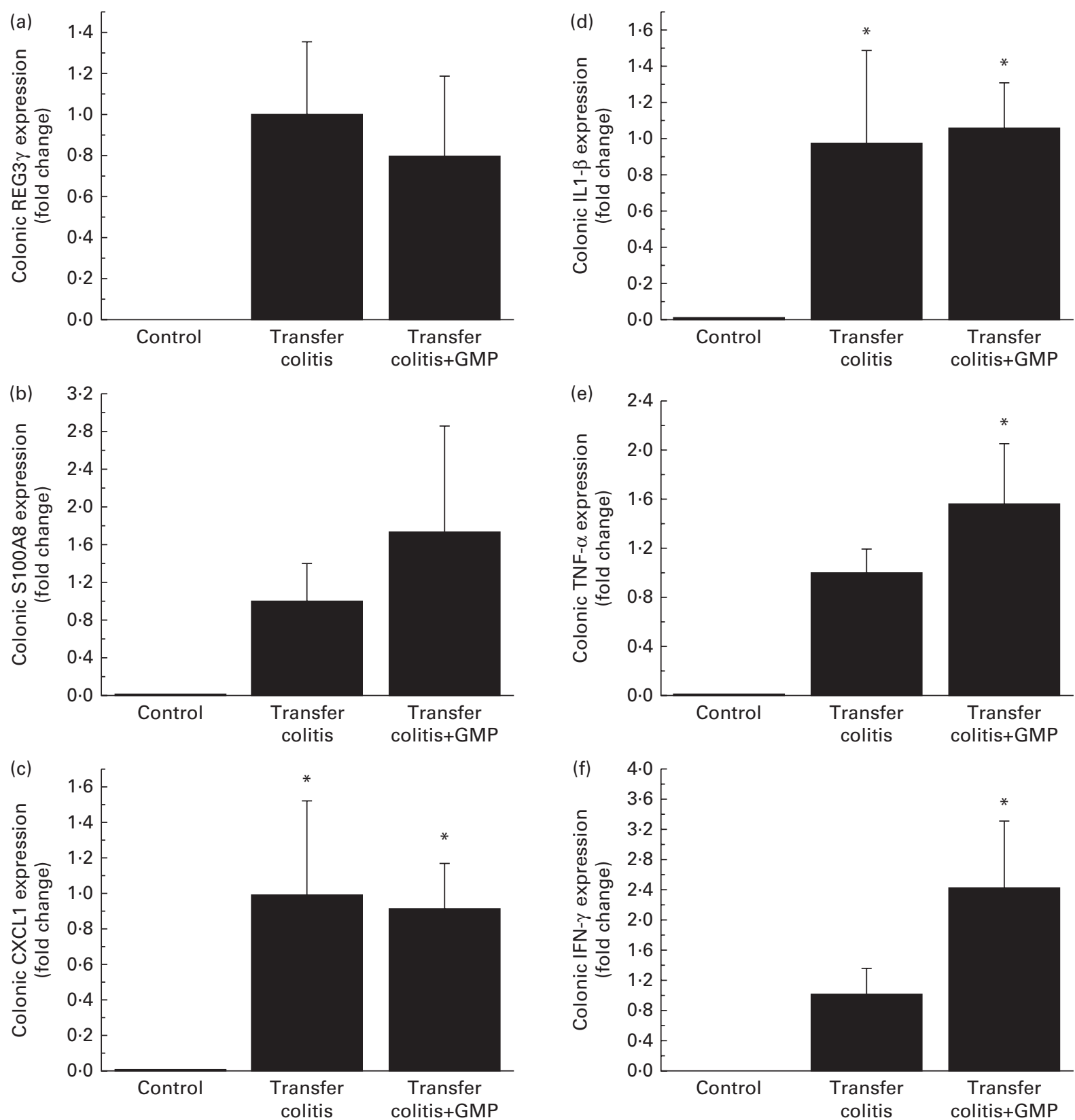

Fig. 3. Colonic expression of inflammatory markers in mice with lymphocyte-driven colitis. Chronic colitis was induced in mice and they were then treated with glycomacropeptide (GMP; $15 \mathrm{mg} / \mathrm{kg}$ ) or vehicle for $13 \mathrm{~d}$. The mRNA levels were measured by RT-PCR. (a) REG3 $\gamma$, (b) S100A8, (c) chemokine (C-X-C motif) ligand 1 (CXCL1), (d) IL-1 $\beta$, (e) TNF- $\alpha$, (f) interferon- $\gamma$ (IFN- $\gamma)$. Values are means, with standard errors represented by vertical bars. * Mean values were significantly different from those of the control group $(P<0.05)$.

In particular, there is an extended lag period until the development of disease, with a significant variation among mice even within a single experiment. The onset of the disease is insidious, making it difficult to judge when the animal is 'ready' for testing. In the present study, we transferred naïve $\mathrm{T}$ lymphocytes into a relatively large number of $\mathrm{Rag}^{-/}$mice and grouped them for further experimentation based on body-weight evolution and other signs of disease such as reduced movement, huddling or diarrhoea (other groups were used for unrelated treatments). Thus, the mice used for this experiment exhibited similar characteristics before randomisation to the administration of GMP orally or vehicle.
It is important to note that the use of this model represents a leap forward in the state of the art in the development of nutraceuticals for intestinal inflammatory conditions.

GMP was administered at a dose of $15 \mathrm{mg} / \mathrm{d}$, which is equivalent to that used successfully as a pre-treatment in rats $(500 \mathrm{mg} / \mathrm{kg})$, based on body surface. This dose is roughly equivalent to $5 \mathrm{~g}$ for an adult human (again on a body surface basis), an amount that cannot be easily achieved by milk consumption, but is easily attainable by consumption of a functional food or a drug. Because of the reasons stated above, the protocol applied in this case is a post-treatment, which is expected to produce less pronounced effects in general. 
(a)

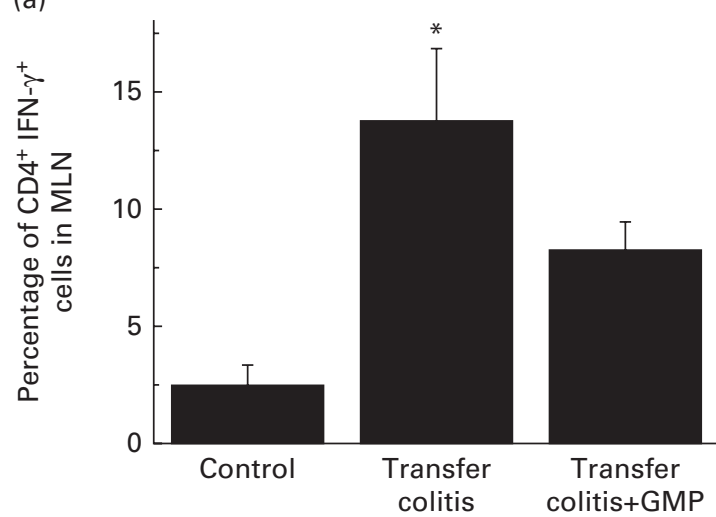

(b)

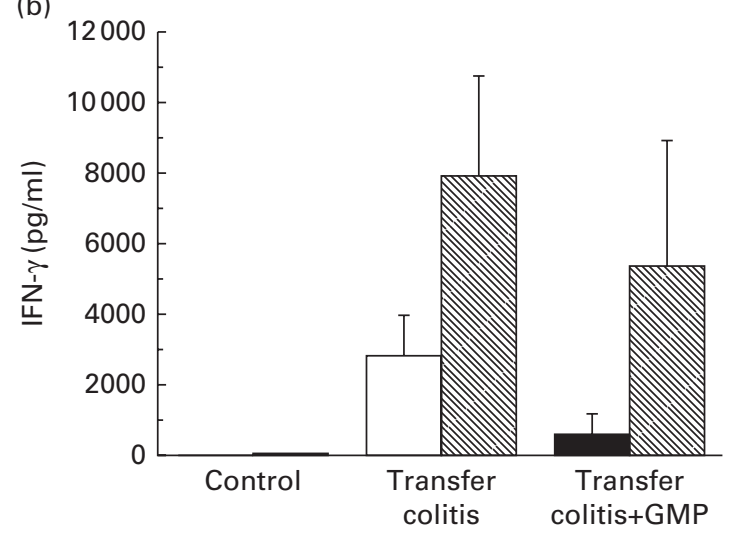

(c)

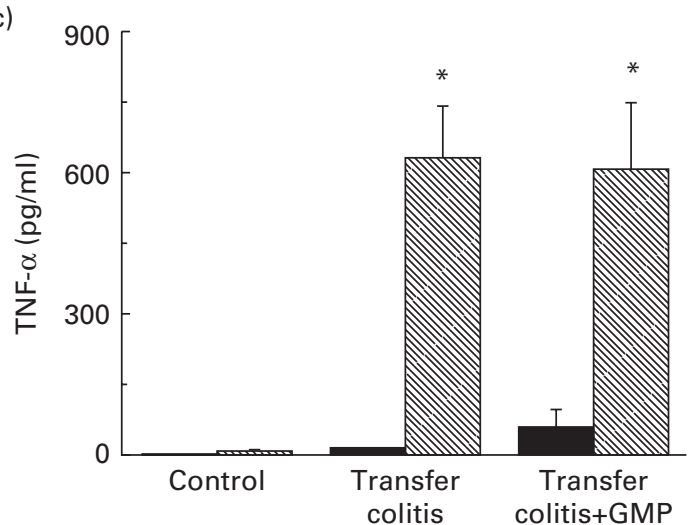

(d)

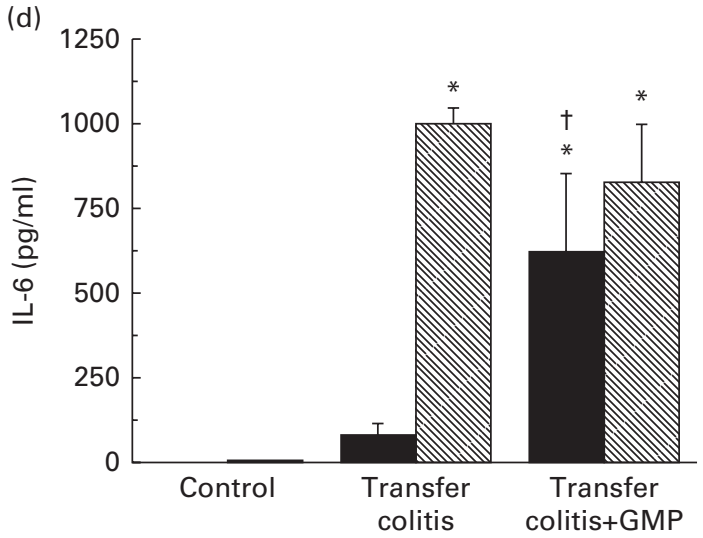

(e)
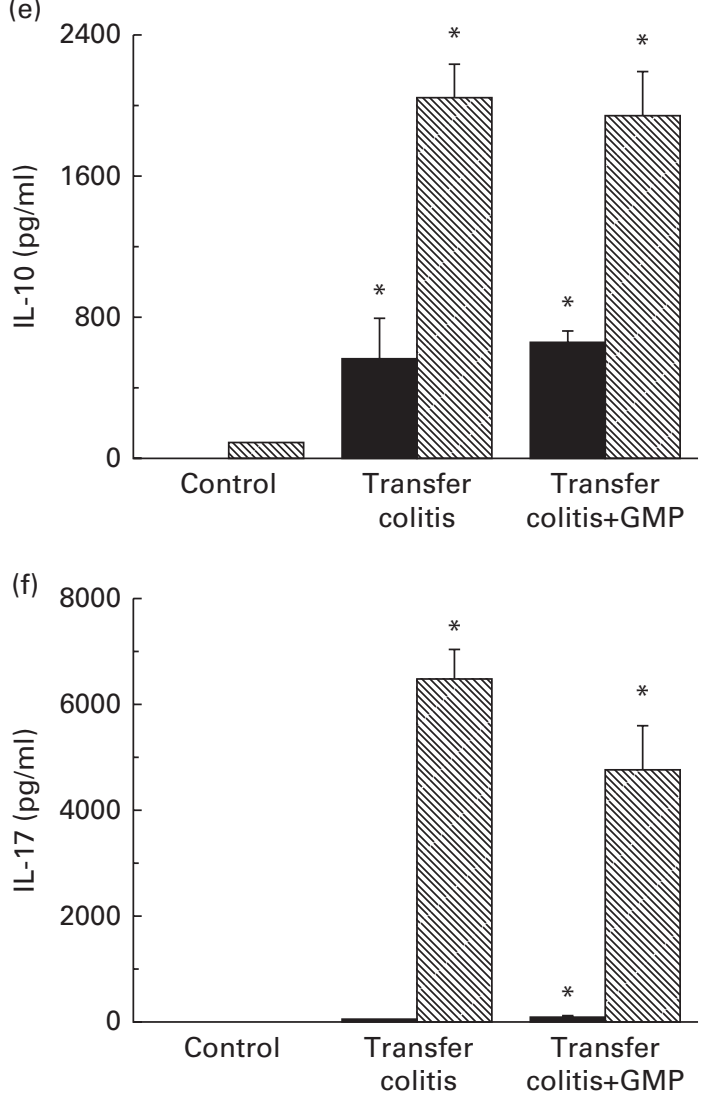

Fig. 4. Cytokine secretion by mesenteric lymph node cells ex vivo in mice with lymphocyte-driven colitis. Chronic colitis was induced in mice and they were then treated with glycomacropeptide (GMP; $15 \mathrm{mg} / \mathrm{kg}$ ) or vehicle for $13 \mathrm{~d}$. Mesenteric lymph node (MLN) cells were isolated and cultured, with or without concanavalin A, and the levels of cytokines in the supernatant were measured by ELISA. (a) Percentage of CD4 ${ }^{+}$IFN- $\gamma^{+}$cells (assessed by flow cytometry), (b) IFN- $\gamma$, (c) TNF- $\alpha$, (d) IL-6, (e) IL-10, (f) IL-17. Values are means, with standard errors represented by vertical bars. * Mean values were significantly different from those of the control group $(P<0.05)$. † Mean value was significantly different from that of the transfer colitis group $(P<0.05)$. $\square$, Basal; $\mathbb{\Xi}$, concanavalin $\mathrm{A}$.

Another possible source of variation is the use of a different species (mouse $v$, rat). In these conditions, GMP exerted significant protective effects. A positive response was anticipated before killing the animals based on a higher body-weight gain (albeit non-significant), which was achieved despite the food intake being similar to that of the control mice. Body-weight loss in acute and semi-chronic models of colitis is mainly a consequence of anorexia, which is part of the acute response. In this model, food intake was within normal boundaries in both the control and GMP-treated mice, suggesting that differences are due to absorptive problems and/or enhanced catabolism.

The large intestine exhibited signs of a relatively mild colitis compared with the harsh impact of TNBS or DSS colitis, with loss of visible vascular patterns (oedema), hyperaemia and thickening, but no necrosis, major adhesions or strictures. This was better evidenced at the histological level, where intense infiltration and crypt enlargement but with only minor areas of epithelial erosion and no overt ulceration were observed. Intestinal thickening was a major sign of 


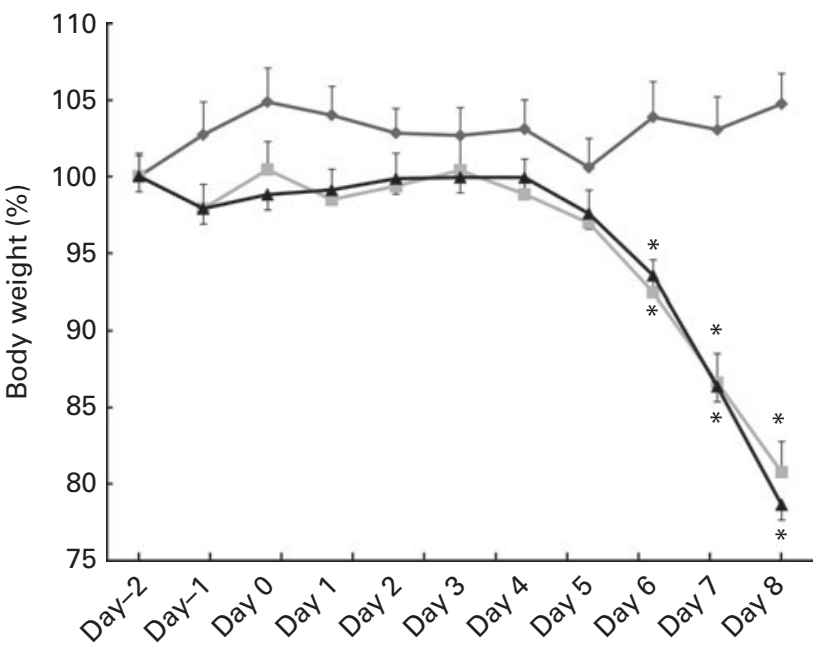

Fig. 5. Body-weight evolution in mice with dextran sulphate sodium (DSS, --) colitis. Colitis was induced in mice with $2 \%$ DSS in drinking-water. Glycomacropeptide (GMP; $15 \mathrm{mg} / \mathrm{kg}$ ) or vehicle was administered $2 \mathrm{~d}$ before DSS treatment and for an additional $7 \mathrm{~d}$. Values are means, with standard errors represented by vertical bars. * Mean values were significantly different from those of the control group $(P<0.05) . \_$, Control; $\_$, DSS+GMP.

colitis, and it was improved by GMP treatment in both the colon and ileum, but without reaching statistical significance. Thus, GMP appears to ameliorate oedema and crypt elongation, but this effect probably requires a bigger group size to be picked up during statistical analysis. The effect of GMP was better evidenced by biochemical analysis. Thus, the activity of colonic MPO was increased 2-fold in the colitic group, consistent with a relatively mild degree of inflammation, and this was fully normalised by GMP treatment, indicating the inhibition of neutrophil infiltration. On the other hand, GMP exerted only a non-significant effect on the activity of colonic AP. The activity of AP is increased in colitis as a result of the combination of an infiltration of leucocytes and a change of isoform expressed at the epithelial level ${ }^{(18)}$. Thus, colonic inflammation is characterised not only by an augmented activity of AP, but also by a higher inhibition by the specific inhibitor levamisole in vitro, as has been observed in the present study. The fact that the activity of MPO was reduced by GMP while that of AP was not suggests that it failed to modulate the epithelial component, in line with its

Table 2. Macroscopic damage parameter values of dextran sulphate sodium (DSS) colitic mice and body weight

(Mean values with their standard errors)

\begin{tabular}{|c|c|c|c|c|c|c|c|c|}
\hline & \multicolumn{2}{|c|}{$\begin{array}{l}\text { Body weight } \\
\text { (\% initial } \\
\text { weight) }\end{array}$} & \multicolumn{2}{|c|}{$\begin{array}{l}\text { Damage } \\
\text { score }\end{array}$} & \multicolumn{2}{|c|}{$\begin{array}{c}\text { Colon } \\
\text { weight/ } \\
\text { length ratio } \\
(\mathrm{mg} / \mathrm{cm})\end{array}$} & \multicolumn{2}{|c|}{$\begin{array}{c}\text { Colon } \\
\text { length }(\mathrm{cm})\end{array}$} \\
\hline & Mean & SE & Mean & SE & Mean & SE & Mean & SE \\
\hline Control & $104 \cdot 7$ & 1.6 & 0 & 0 & $21 \cdot 1$ & 0.6 & $7 \cdot 9$ & 0.3 \\
\hline DSS & $80 \cdot 8^{\star}$ & 1.6 & $3 \cdot 0^{*}$ & 0.5 & $30 \cdot 8^{\star}$ & 1.4 & $5 \cdot 4^{\star}$ & 0.3 \\
\hline GMP & $78 \cdot 7^{\star}$ & 1.6 & $2 \cdot 8^{*}$ & 0.5 & $31 \cdot 7^{*}$ & $2 \cdot 2$ & $5 \cdot 4^{*}$ & 0.3 \\
\hline
\end{tabular}

GMP, glycomacropeptide.

${ }^{*}$ Mean values were significantly different from those of the control group $(P<0.05)$.

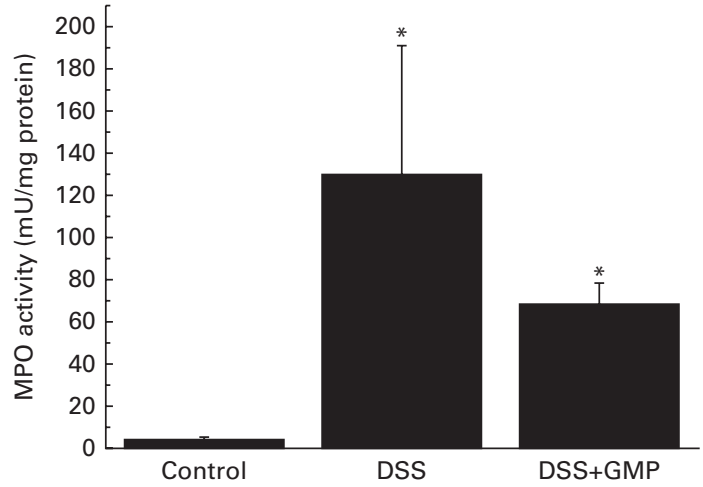

Fig. 6. Colonic myeloperoxidase (MPO) activity in mice with dextran sulphate sodium (DSS) colitis. Colitis was induced in mice with $2 \%$ DSS in drinkingwater. Glycomacropeptide (GMP; $15 \mathrm{mg} / \mathrm{kg}$ ) or vehicle was administered $2 \mathrm{~d}$ before DSS treatment and for an additional $7 \mathrm{~d}$. Values are means, with standard errors represented by vertical bars. * Mean values were significantly different from those of the control group $(P<0.05)$

documented lack of activity in epithelial cells. In fact, the in vitro experiments carried out in the present study indicate that GMP is inactive in modulating epithelial repair, antibacterial defence or cytokine secretion, in line with this hypothesis.
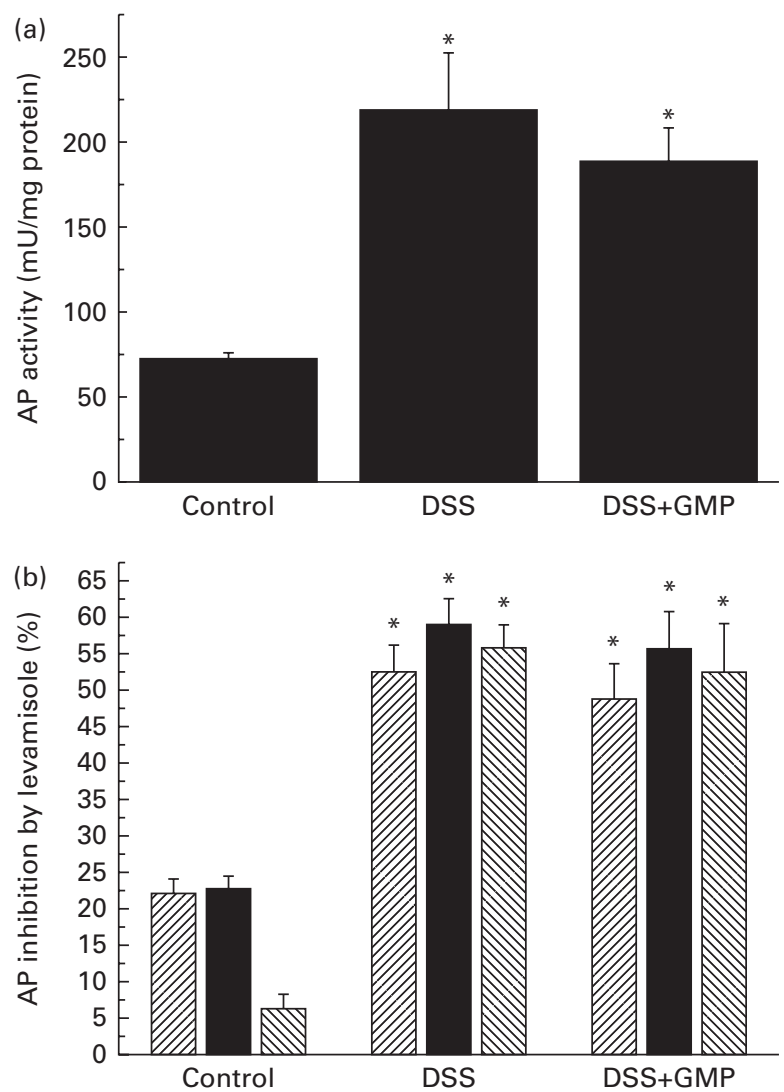

Fig. 7. Alkaline phosphatase (AP) activity in mice with dextran sulphate sodium (DSS) colitis. Colitis was induced in mice with $2 \%$ DSS in drinkingwater. Glycomacropeptide (GMP; $15 \mathrm{mg} / \mathrm{kg}$ ) or vehicle was administered $2 \mathrm{~d}$ before DSS treatment and for an additional $7 \mathrm{~d}$. (a) AP activity, (b) Inhibition of AP activity by levamisole in vitro. Values are means, with standard errors represented by vertical bars. * Mean values were significantly different from those of the control group $(P<0.05)$. $\square$, Levamisole $0.1 \mathrm{~mm}$; levamisole $1 \mathrm{~mm} ; \mathbb{\nabla}$, levamisole $10 \mathrm{~mm}$ 

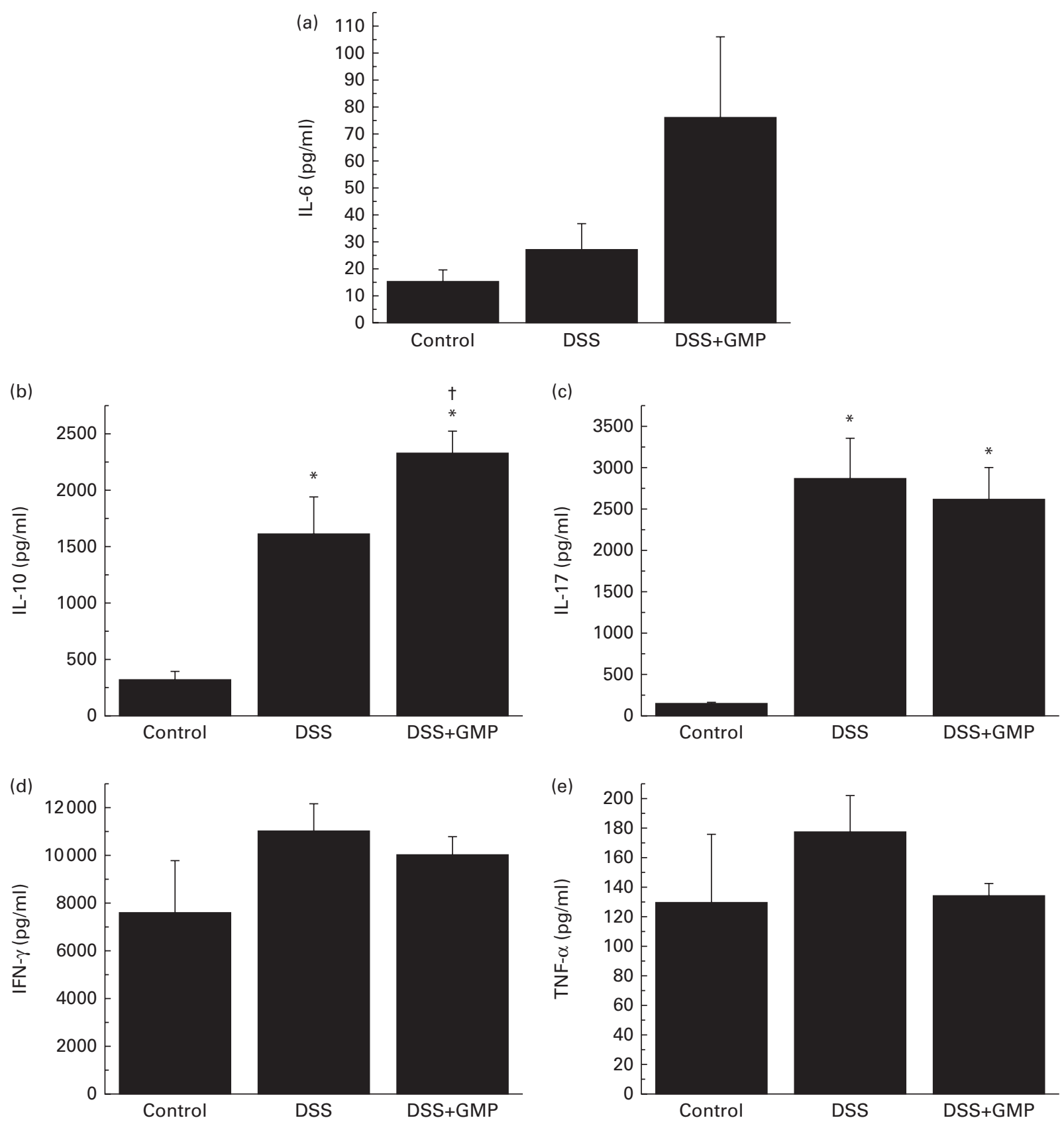

Fig. 8. Cytokine secretion by mesenteric lymph node cells ex vivo in mice with dextran sulphate sodium (DSS) colitis. Colitis was induced in mice with $2 \%$ DSS in drinking-water. Glycomacropeptide (GMP; $15 \mathrm{mg} / \mathrm{kg}$ ) or vehicle was administered $2 \mathrm{~d}$ before DSS treatment and for an additional $7 \mathrm{~d}$. Values are means, with standard errors represented by vertical bars. ${ }^{*}$ Mean values were significantly different from those of the control group $(P<0.05)$. $\dagger$ Mean value was significantly different from that of the transfer colitis group $(P<0.05)$. $\mathbf{n}$, Concanavalin A $5 \mu \mathrm{g} / \mathrm{ml}$. IFN, interferon.

However, we cannot completely exclude the possibility of epithelial actions because of the limitations imposed by the use of intestinal epithelial cell lines. Thus, it remains possible that GMP exerts significant effects on the epithelium in vivo. This is very difficult to assess directly, because primary enterocytes generally have an extremely limited lifespan.

Other biochemical inflammatory markers indicative of ongoing inflammation are the up-regulated parameters measured by RT-PCR in colonic tissue and the cytokines released by MLN cells ex vivo ${ }^{(20)}$. The effects of GMP at this level are complex, but they are generally consistent with the dual action previously observed with this peptide, boosting innate immunity but blocking adaptive immunity. In this regard, it is interesting that GMP is associated with an increase in the production of IL- 6 . We ${ }^{(21)}$ and others ${ }^{(22)}$ have noted the stimulatory effect of GMP on macrophages, in terms of cytokine production and phagocytic activity. GMP may interfere with IL-1 $\beta$ receptor binding ${ }^{(23)}$. Conversely, GMP has been described to inhibit the proliferation of splenocytes and Peyer's patch cells ${ }^{(24)}$. We have recently observed that 

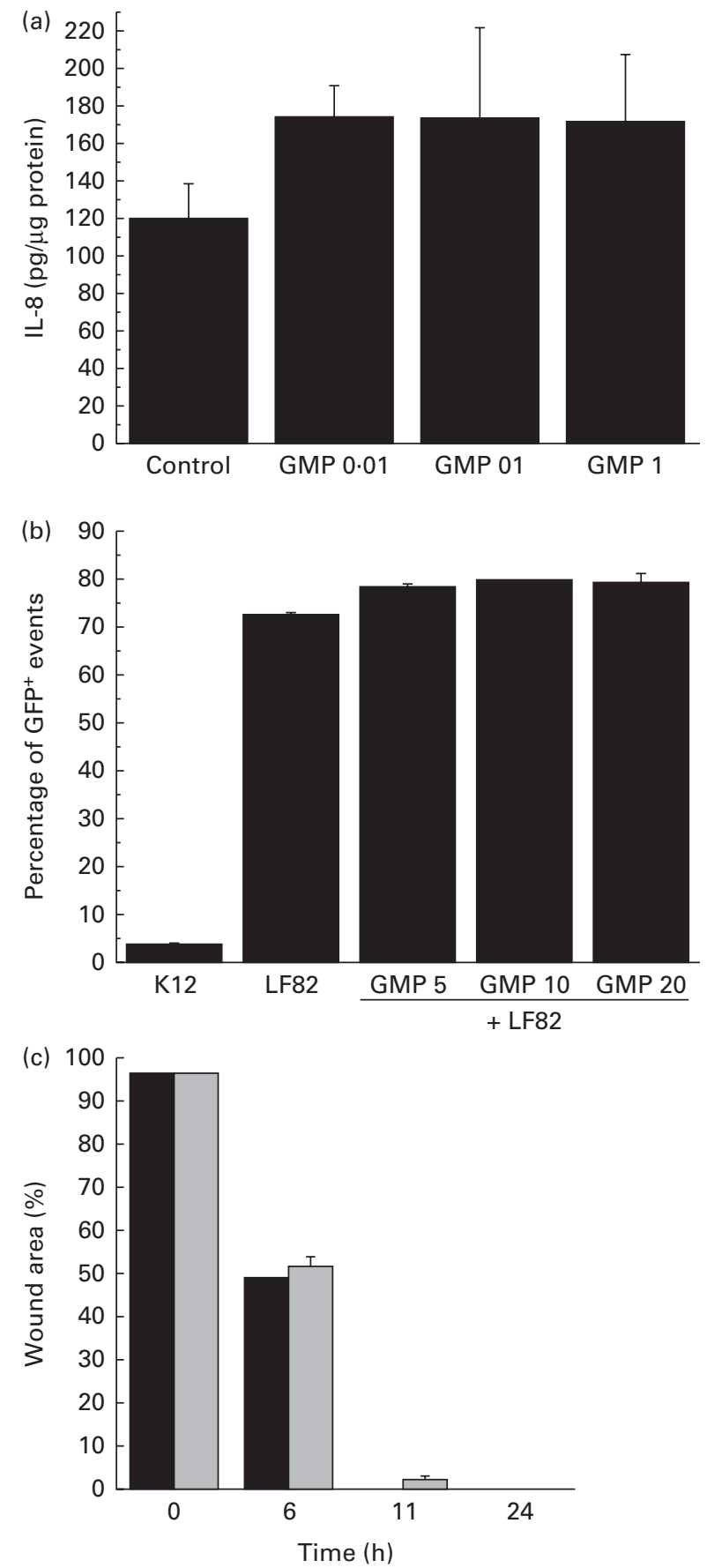

Fig. 9. Effect of glycomacropeptide (GMP) in intestinal epithelial cells. (a) Effect on the secretion of IL-8 by HT29 cells (GMP 0.01-1 g/l), (b) Effect on bacterial invasion in IEC18 cells. Cells containing green fluorescent protein (GFP)-expressing bacteria are detected as $\mathrm{GFP}^{+}$events and represented as a percentage of total cells, (c) Effect on wound healing in IEC18 cells. There was no significant effect of GMP in any case. $\square$, Control; $\square$, GMP $1 \mathrm{~g} / \mathrm{l}$.

GMP inhibits the release of IFN- $\gamma$ by rat splenocytes by blocking STAT4 activation ( $F$ Sánchez de Medina and O Martínez-Augustin, unpublished results). However, the production of IgG by mouse B lymphocytes seems to be increased by $\mathrm{GMP}^{(25)}$. Therefore, it is possible that GMP acts by modulating the functions of lymphocytes and macrophages so as to enhance intestinal barrier function and dampen colitis.
At any rate, the mechanism of the action of GMP must involve the MLN cell population or monocytes and lymphocytes in the lamina propria, since it has no effect on epithelial cells. IL-6 may be a common factor in both the models, as has been mentioned above.

It is interesting to compare these data with those obtained in the mouse DSS model. We carried out the present study originally as a preliminary stage to examine the involvement of macrophages $v$. lymphocytes in the effects of GMP, namely applying the DSS model to Rag $1^{-/-}$mice. The present results indicate that although GMP exerts a beneficial effect in regular C57BL/6 mice, the magnitude of the effect is certainly diminished compared with that observed in rat colitis or ileitis. Clinical improvement was evidenced by the amelioration of the activity of colonic MPO and increased production of IL-10 by MLN cells ex vivo. Taken together, our findings indicate that GMP is active in several different models of intestinal inflammation, but the results differ depending on animal species and experimental model, with rats being more sensitive than mice and TNBS being more effective than DSS. DSS is thought to elicit intestinal inflammation by slowly altering the epithelial integrity, augmenting permeability and ultimately resulting in an immune reaction against luminal antigens ${ }^{(26)}$. In contrast, TNBS acts as a hapten by a delayed hypersensitivity mechanism involving the reaction with mucosal proteins ${ }^{(27)}$. Oxidative stress may also play a role ${ }^{(28)}$. The epithelium, therefore, plays a more important role in DSS colitis than in TNBS colitis, and since, as noted, GMP has no effect on the epithelium, it is logical that less pronounced effects are observed in the former model. Another example of this disparate behaviour is the effect of the flavonoid luteolin in DSS and IL- $10^{-/-}$colitis in mice, being deleterious in the former and protective in the latter ${ }^{(29)}$, a discrepancy explained by the inhibitory action of the flavonoid on the NF- $\mathrm{B}$ pathway in the epithelium, which may compromise the defence of the mucosa towards epithelial disruption by DSS.

In conclusion, our data validate the intestinal anti-inflammatory activity of GMP in chronic, lymphocyte-driven colitis, considered one of the best models of colitis because of its resemblance to human IBD.

\section{Acknowledgements}

The authors are grateful to Dr Mercedes González for her assistance and also to Dr Arlette Darfeuille Michaud for providing the bacterial strains. They are also thankful to Davisco Foods International, Inc. for providing GMP.

The present study was supported by grants from Fundación Ramón Areces and by the Instituto de Salud Carlos III (PI051625 and PI051651) and the Ministry of Economy and Competitivity (SAF2008-01432, AGL2008-04332, SAF201122922 and SAF2011-22812) and by funds from Junta de Andalucía (CTS6736 and CTS164). None of the funders had any role in the design and analysis of the study or in the writing of this article. CIBERehd is funded by the Instituto de Salud Carlos III. M. O.-G., P. R., B. O. and C. A. are funded by the Ministry of Education. 
The authors' contributions are as follows: M. O.-G., F. C.-C., P. R., B. O., I. R.-C. and C. A. carried out the experiments; M. D. S., A. Z., F. S. d. M. and O. M.-A. designed the experiments; F. S. d. M. and O. M.-A. wrote the manuscript. All authors contributed to the discussion and overall structure of the manuscript.

None of the authors has any conflicts of interest to declare.

\section{References}

1. Ekbom A (2004) The epidemiology of IBD: a lot of data but little knowledge. How shall we proceed? Inflamm Bowel Dis 10, Suppl. 1, S32-S34

2. Sands BE (2007) Inflammatory bowel disease: past, present, and future. J Gastroenterol 42, 16-25.

3. Nenci A, Becker C, Wullaert A, et al. (2007) Epithelial NEMO links innate immunity to chronic intestinal inflammation. Nature 446, 557-561.

4. Sainathan SK, Hanna EM, Gong Q, et al. (2008) Granulocyte macrophage colony-stimulating factor ameliorates DSSinduced experimental colitis. Inflamm Bowel Dis 14, 88-99.

5. Qualls JE, Kaplan AM, van Rooijen N, et al. (2006) Suppression of experimental colitis by intestinal mononuclear phagocytes. J Leukoc Biol 80, 802-815.

6. Qualls JE, Tuna H, Kaplan AM, et al. (2009) Suppression of experimental colitis in mice by $\mathrm{CD} 11 \mathrm{c}^{+}$dendritic cells. Inflamm Bowel Dis 15, 236-247.

7. Brody EP (2000) Biological activities of bovine glycomacropeptide. Br J Nutr 84, S39-S46.

8. Nakano T, Silva-Hernandez ER, Ikawa N, et al. (2002) Purification of kappa-casein glycomacropeptide from sweet whey with undetectable level of phenylalanine. Biotechnol Prog 18, 409-412.

9. Nakay S \& Modler HW (1999) Food Proteins. Processing Applications. New York, NY: Wiley-VCH.

10. Lopez-Posadas R, Requena P, Gonzalez R, et al. (2010) Bovine glycomacropeptide has intestinal antiinflammatory effects in rats with dextran sulfate-induced colitis. I Nutr 140, 2014-2019.

11. Sánchez de Medina F, Daddaoua A, Requena P, et al. (2010) New insights into the immunological effects of food bioactive peptides in animal models of intestinal inflammation. Proc Nutr SOC 69, 454-462.

12. Requena P, Daddaoua A, Martínez-Plata E, et al. (2008) Bovine glycomacropeptide ameliorates experimental rat ileitis by mechanisms involving downregulation of interleukin 17. Br J Pharmacol 154, 825-832.

13. Daddaoua A, Puerta V, Zarzuelo A, et al. (2005) Bovine glycomacropeptide is anti-inflammatory in rats with hapten-induced colitis. J Nutr 135, 1164-1170.

14. Koboziev I, Karlsson F, Zhang S, et al. (2011) Pharmacological intervention studies using mouse models of the inflammatory bowel diseases: translating preclinical data into new drug therapies. Inflamm Bowel Dis 17, 1229-1245.
15. Pérez-Navarro R, Ballester I, Zarzuelo A, et al. (2005) Disturbances in epithelial ionic secretion in different experimental models of colitis. Life Sci 76, 1489-1501.

16. Ito $\mathrm{H}$, Tanabe $\mathrm{H}$, Kawagishi $\mathrm{H}$, et al. (2009) Short-chain inulin-like fructans reduce endotoxin and bacterial translocations and attenuate development of TNBS-induced colitis in rats. Dig Dis Sci 54, 2100-2108.

17. Krawisz JE, Sharon P \& Stenson WF (1984) Quantitative assay for acute intestinal inflammation based on myeloperoxidase activity. Assessment of inflammation in rat and hamster models. Gastroenterology 87, 1344-1350.

18. Lopez-Posadas R, Gonzalez R, Ballester I, et al. (2011) Tissue-nonspecific alkaline phosphatase is activated in enterocytes by oxidative stress via changes in glycosylation. Inflamm Bowel Dis 17, 543-556.

19. Ostanin DV, Bao J, Koboziev I, et al. (2009) T cell transfer model of chronic colitis: concepts, considerations, and tricks of the trade. Am J Physiol Gastrointest Liver Physiol 296, G135-G146.

20. Hirano D \& Kudo S (2009) Usefulness of CD4 ${ }^{+}$CD 45 RBhigh CD25 cell-transferred SCID mice for preclinical evaluation of drugs for inflammatory bowel disease. J Pharmacol Sci 110, 169-181.

21. Requena P, Daddaoua A, Guadix E, et al. (2009) Bovine glycomacropeptide induces cytokine production in human monocytes through the stimulation of the MAPK and the NF-kappaB signal transduction pathways. Br J Pharmacol 157, 1232-1240

22. Fomon SJ (1993) Nutrition of Normal Infants. St Louis: Mosby Yearbook, Inc.

23. Monnai M \& Otani H (1997) Effect of bovine k-caseinoglycopeptide on secretion of interleukin-1 family cytokines by P388D1 cells, a line derived from mouse monocyte/macrophage. Milchwissenschaft - Milk Sci Int 52, 192-196.

24. Otani H \& Hata I (1995) Inhibition of proliferative responses of mouse spleen lymphocytes and rabbit Peyer's patch cells by bovine milk caseins and their digests. I Dairy Res $\mathbf{6 2}$, $339-348$.

25. Monnai M, Horimoto Y \& Otani H (1998) Immunomodificatory effect of dietary bovine kappa-caseinoglycopeptide on serum antibody levels and proliferative responses of lymphocytes in mice. Milchwissenschaft - Milk Sci Int $\mathbf{5 3}$, 129-132.

26. Cooper HS, Murthy SN, Shah RS, et al. (1993) Clinicopathologic study of dextran sulfate sodium experimental murine colitis. Lab Invest 69, 238-249.

27. Morris GP, Beck PL, Herridge MS, et al. (1989) Hapteninduced model of chronic inflammation and ulceration in the rat colon. Gastroenterology 96, 795-803.

28. Grisham MB, Volkmer C, Tso P, et al. (1991) Metabolism of trinitrobenzene sulfonic acid by the rat colon produces reactive oxygen species. Gastroenterology 101, 540-547.

29. Karrasch T, Kim JS, Jang BI, et al. (2007) The flavonoid luteolin worsens chemical-induced colitis in NF-kappaB (EGFP) transgenic mice through blockade of NF-kappaB-dependent protective molecules. PLOS ONE 2, e596. 